\title{
The Different Characteristics of Aquifer Parameters and Their Implications on Pumping-Test Analysis
}

\author{
by J. J. Jiao and C. Zheng ${ }^{\mathrm{a}}$
}

\begin{abstract}
The concepts of two-way coordinates and one-way coordinates are used to describe the different characteristics of two key aquifer parameters, transmissivity and storativity, under constant-rate pumping conditions. A two-way coordinate is such that the conditions at a given location are influenced by changes in conditions on either side of that location; a one-way coordinate is such that the conditions at a given location are influenced by changes in conditions on only one side of that location. Results from sensitivity analysis indicate that storativity has the characteristics of two-way coordinates, but transmissivity has the characteristics of one-way coordinates, i.e., its information can be transferred mainly from upstream to downstream. An upstream observation well can produce information on storativity both upstream and downstream, but it can produce little information on transmissivity downstream.

These characteristics of the aquifer parameters have important implications on pumping-test designs and interpretation. For example, to estimate the parameters of an anomalous zone in an aquifer, an observation well should be located downstream but near the zone. It should not be placed upstream if the parameters downstream are to be estimated. An observation well which can provide adequate information for estimating storativity may not provide adequate information for estimating transmissivity, and vice versa. The aquifer area represented by estimated storativity may be different from that represented by estimated transmissivity.
\end{abstract}

\section{Introduction}

The influence of heterogeneities on aquifer parameter estimation based on pumping tests has received much attention for years. A sensitivity analysis is used as an important approach to understand the behavior of hydraulic parameters in an aquifer with zones which have parameters significantly different from those of the background aquifer (e.g., McElwee, 1982; Butler, 1988; Butler and McElwee, 1990; Jiao, 1995). The findings about the features of these anomalous zones in the context of pumpingtest analyses can be summarized as the following: (1) A parameter can be best estimated from drawdown-time data when the sensitivity of the parameter is not only large but also changing significantly with time; (2) The influence of anomalous zones on drawdown during a pumping test lasts only a limited time; (3) The influence of a zone less permeable than the background aquifer material is much larger than that of a zone more permeable; and (4) It is easier to estimate transmissivity than storativity because transmissivity sensitivity is usually much larger than storativity sensitivity.

It has been demonstrated that the area represented by the estimated parameters is much smaller than that covered by the cone of depression (Jiao, 1993). Therefore, after parameters are estimated, it may be of interest to know what portion of the aquifer is primarily represented by the estimated parameters. Before a pumping test, it may also be necessary to design the location of an observation well in such a way that the information on a particular portion of the aquifer can be best obtained. This requires an understanding of the relationships among the

\footnotetext{
${ }^{a}$ Department of Geology, University of Alabama, P. O. Box 870338, Tuscaloosa, Alabama 35487. 1995.

Received April 1995, revised October 1995, accepted November
}

characteristics of aquifer parameters, flow field, and the spatial coordinates.

While most studies are concerned with the general features of the properties of anomalous zones, Oliver (1993) seems to be the first to concentrate specifically on the different characteristics of transmissivity and storativity in response to pumping. $\mathrm{He}$ concluded, based on a particular case study, that the influence of storativity is nearly radially symmetric so that the effect of a low-storativity region is essentially the same in any direction, but the influence of transmissivity on drawdown at observation wells is not spatially uniform within that area. This suggests that storativity and transmissivity have different characteristics related to spatial coordinates.

An attempt is made in this paper to examine the different characteristics of transmissivity and storativity under constantrate pumping conditions using numerical simulations. Two concepts, two-way coordinates and one-way coordinates, which were first used in numerical heat transfer and fluid flow (Patankar, 1980), are introduced to understand the characteristics of these two parameters. A two-way coordinate is such that the conditions at a given location are influenced by changes in conditions on either side of that location; a one-way coordinate is such that the conditions at a given location are influenced by changes in conditions on only one side of that location. For example, the flow field between two rivers provides an example of two-way coordinates. The head at any given point in the flow field is influenced by changing the head of either river. Another example is solute transport. For dispersion-dominated problems, space coordinates are two-way coordinates. But a space coordinate can very nearly become one-way under advection. If there is a strong unidirectional flow in the coordinate direction, significant influence travels only from upstream to downstream. Conditions at a point are then affected largely by the upstream conditions and very little by the downstream ones. Advection is a 
one-way process, but dispersion has two-way influence. For advection-dispersion problems the properties of space coordinates have the dual properties of one-way and two-way coordinates. When the velocity is large, advection dominates over dispersion and thus makes the space coordinate nearly one-way. It becomes necessary to use special numerical methods such as upstream-weighted methods and characteristics methods to account for one-way properties of spatial coordinates in advection-dominated problems (Jiao and Chen, 1987; Zheng and Bennett, 1995).

In this paper, the sensitivity features of drawdown to aquifer parameters under constant-rate pumping conditions in onedimensional flow systems are first examined to investigate the different characteristics of transmissivity and storativity. The influence of the location of an anomalous zone on drawdown in an observation well is further studied by analyzing the sensitivity features of aquifer parameters in radial one-dimensional flow systems. Finally, the impact of the characteristics of transmissivity and storativity on their estimation is demonstrated using a hypothetical example.

\section{Sensitivity Analysis}

A sensitivity analysis is the study of a system's response to various disturbances. The response of the aquifer system may be expressed in terms of drawdown or hydraulic head. Because pumping-test analysis is of particular concern, drawdown, $s$, is used. Mathematically, the sensivitity is the partial derivative of drawdown with respect to a model parameter. For example, the sensitivity of drawdown to transmissivity, T, can be defined as:

$$
\mathrm{U}_{\mathrm{T}}=\frac{\partial \mathrm{s}}{\partial \mathrm{T}}
$$

A disadvantage of the sensitivity defined by equation (1) is that the magnitude depends on the dimension and unit of the particular parameter. A normalized sensitivity can be defined as (e.g., McElwee, 1987):

$$
\mathrm{U}_{\mathrm{T}}^{\prime}=\mathrm{T} \frac{\partial \mathrm{s}}{\partial \mathrm{T}}=\frac{\partial \mathrm{s}}{\partial \mathrm{T} / \mathrm{T}}
$$

The normalized sensitivity describes the influence of ratio change in a parameter. Thus, normalized sensitivities can be readily plotted together and compared. The storativity sensitivity $U_{S}$ or normalized storativity sensitivity $U_{S}^{\prime}$ can be defined in the same way. In terms of parameter estimation, the absolute magnitude of a sensitivity, not its signed value, is of importance. In the following discussion, when the word "sensitivity" is used, the absolute magnitude of sensitivity is implied.

There are three methods for determining sensitivity coefficients of aquifer parameters: (1) analytical expressions; (2) numerical solution of a partial differential equation; and (3) finite-difference approximations (Beck and Arnold, 1977). For simple ground-water problems, there are analytical expressions for parameter sensitivity. When analytical solutions are not available, numerical solutions can be used to determine sensitivity. Sensitivity equations can be easily derived from flow equations and solved by conventional numerical approaches used for flow modeling. For instance, sensitivity equations were solved by Sykes et al. (1985) using the Galerkin finite-element method to assess the uncertainty of prospective radioactive waste repositories. Jiao (1993) solved sensitivity equations modified from a

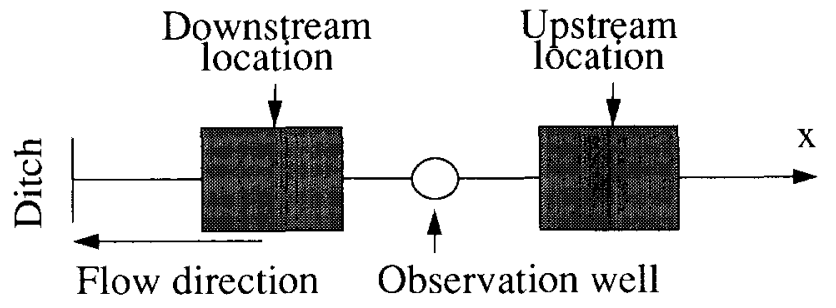

Fig. 1. Schematic representation of an observation well, and the upstream and downstream locations of an anomalous zone in onedimensional flow field. (Background aquifer parameters $T^{\prime}=60 \mathrm{~m}^{2} / \mathrm{d}$, $S^{\prime}=6 \times 10^{-3} ;$ zone parameters $T^{\prime}=6 \mathrm{~m}^{2} / \mathrm{d}, S^{\prime}=6 \times 10^{-4}$ ).

radial numerical flow model by Rushton and Chan (1976) to understand the sensitivity features of pumping-test drawdown to aquifer parameters. However, the easiest and most straightforward method is the finite-difference approximation. For example, by running the flow model twice with two slightly different values of a parameter, say $T$, the sensitivity is simply given by:

$$
\mathrm{U}_{\mathrm{T}} \approx \Delta \mathrm{s} / \Delta \mathrm{T}=\frac{\mathrm{s}(\mathrm{T}+\Delta \mathrm{T})-\mathrm{s}(\mathrm{T})}{\Delta \mathrm{T}}
$$

The approximation becomes increasingly accurate as $\Delta \mathrm{T}$ approaches zero. Jiao (1993) demonstrated that, for radial flow, the sensitivities evaluated from the above approximation are virtually identical to those using a numerical solution to the corresponding partial differential sensitivity equations.

In this paper, for sensitivity analysis in simple onedimensional flow, the finite-difference approximation is used. For sensitivity analysis in radial one-dimensional flow, the sensitivity equation modified from a radial numerical flow model (Jiao, 1993) is used. The details on how sensitivity equations are derived from flow equations and then solved numerically can be found elsewhere (e.g., McElwee, 1987; Jiao, 1993).

\section{Characteristics of Aquifer Parameters in One-Dimensional Flow}

Consider a semi-infinite aquifer (Figure 1). The left boundary is a fully penetrating ditch. The parameters of the aquifer are $\mathrm{T}^{\prime}=60 \mathrm{~m}^{2} / \mathrm{d}, \mathrm{S}^{\prime}=6 \times 10^{-3}$. After time $\mathrm{t}>0$, water is pumped out from the ditch at a constant rate $q=0.025 \mathrm{~m}^{2} / \mathrm{d}$. A simple finite-difference model with space increment $\Delta x=100 \mathrm{~m}$ is used to simulate the drawdown in the aquifer. The right boundary is chosen to be at $1000 \mathrm{~km}$ so that no drawdown is observed at the boundary during the pumping period of 100 days. An observation well is located at $\mathrm{x}=900 \mathrm{~m}$. Assume that there is an anomalous zone of $200 \mathrm{~m}$ long which has parameter $T=6 \mathrm{~m}^{2} / \mathrm{d}$, $\mathrm{S}=6 \times 10^{-4}$, and is $300 \mathrm{~m}$ from the observation well. The different influence of this zone on drawdown at the observation well when the zone is located downstream and upstream of the well will be investigated.

Figure $2 \mathrm{a}$ shows how the normalized sensitivity of dimensionless drawdown $\left[\left(2(\pi)^{1 / 2} \mathrm{~T}^{\prime} \mathrm{s}\right) /(\mathrm{q} \Delta \mathrm{x})\right]$ to downstream zone storativity $\left(S_{d}\right)$ and upstream zone storativity $\left(S_{u}\right)$ changes with dimensionless pumping time $\left[T^{\prime} t / S^{\prime}(\Delta x)^{2}\right]$. Although the downstream storativity is always more sensitive than the upstream storativity, the difference becomes small as pumping continues.

Figure $2 b$ shows how the normalized sensitivity of dimensionless drawdown to downstream zone transmissivity $\left(T_{d}\right)$ and 
upstream zone transmissivity $\left(T_{u}\right)$ changes with dimensionless pumping time. The $T_{d}$ sensitivity increases to a maximum and then gradually decreases with time, but $T_{u}$ sensitivity increases with time during the whole pumping period. The $T_{u}$ sensitivity is generally much larger than $T_{d}$ sensitivity except at the very beginning of pumping when the aquifer near the upstream zone is not yet disturbed.

Comparison of Figures $2 \mathrm{a}$ with $2 \mathrm{~b}$ shows that the difference between $S_{d}$ and $S_{u}$ is generally much smaller than that between $T_{d}$ and $T_{u}$. As time increases, the former decreases significantly and the latter increases. In terms of storativity, the influence of the upstream and downstream zones on the drawdown in the observation well is of the same order of magnitude, but, in terms of transmissivity, the influence of the upstream zone is much more significant. This indicates that transmissivity has the characteristics of one-way coordinates and storativity has the characteristics of two-way coordinates. These characteristics become more obvious as pumping continues.

The different magnitudes of the sensitivity values shown in Figure 2 have important implication in parameter estimation. It is much easier to estimate transmissivity of the zone than storativity because transmissivity sensitivity is much larger than storativity sensitivity; it is much easier to estimate the upstream transmissivity of the zone than to estimate the downstream transmissivity because $T_{u}$ is much larger than $T_{d}$. When the sensitivity of zone storativity approaches a constant as shown in Figure 2a, essentially no information can be gained about the storage properties of the zone from the drawdown data. The same is true for the transmissivity of the downstream zone. More detailed discussion about these general sensitivity features of anomalous zones can be found in Butler and McElwee (1990), Butler and Liu (1993), and Jiao (1993).
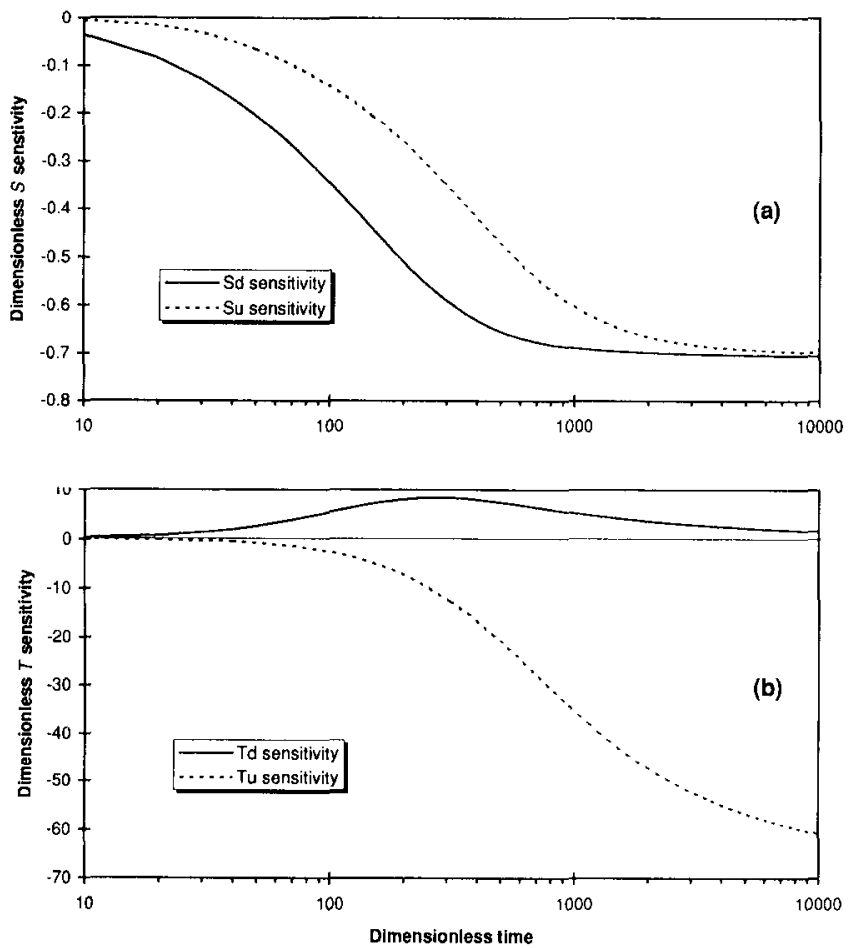

Fig. 2. Change of normalized sensitivities of dimensionless drawdowns $\left[\left(2(\pi)^{1 / 2} T^{\prime} s\right) /(q \Delta x)\right]$ to (a) storativity and (b) transmissivity of downstream and upstream zones with dimensionless time $\left[T^{\prime} t / S^{\prime}(\Delta x)^{2}\right]$.

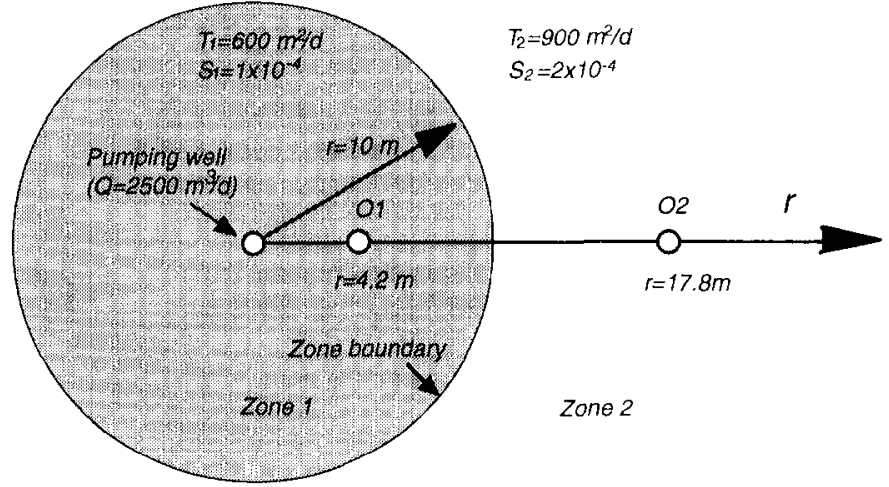

Fig. 3. Schematic representation of two-zone aquifer in a radially symmetric system.

\section{Characteristics of Aquifer Parameters in Radially One-Dimensional Flow Field}

Consider a radially symmetric aquifer of two zones. The aquifer configuration, well locations, pumping rate, and parameters are shown in Figure 3. The aquifer is assumed to be confined and extended to infinity.

Figure 4 shows how the normalized sensitivities of dimensionless drawdown $\left[\left(4 \pi \mathrm{T}_{2} \mathrm{~S}\right) / \mathrm{Q}\right]$ to $\mathrm{S}_{1}$ and $\mathrm{T}_{1}$ change with dimensionless time $\left(\mathrm{T}_{2} \mathrm{t} / \mathrm{S}_{2} \mathrm{l}^{2}\right)$, where $\mathrm{l}$ is the radius of inner zone. The general sensitivity features shown in Figure 4 have been discussed in detail (Jiao, 1993). What is of interest here is the different characteristics between transmissivity and storativity. Figure 4a shows that the maximum storativity sensitivity for the well at $17.8 \mathrm{~m}$ is about $17 \%$ of that at $4.2 \mathrm{~m}$. However, Figure $4 \mathrm{~b}$ shows that the maximum transmissivity sensitivity at $17.8 \mathrm{~m}$ is only about $3 \%$ of that at $4.2 \mathrm{~m}$. This indicates that an upstream
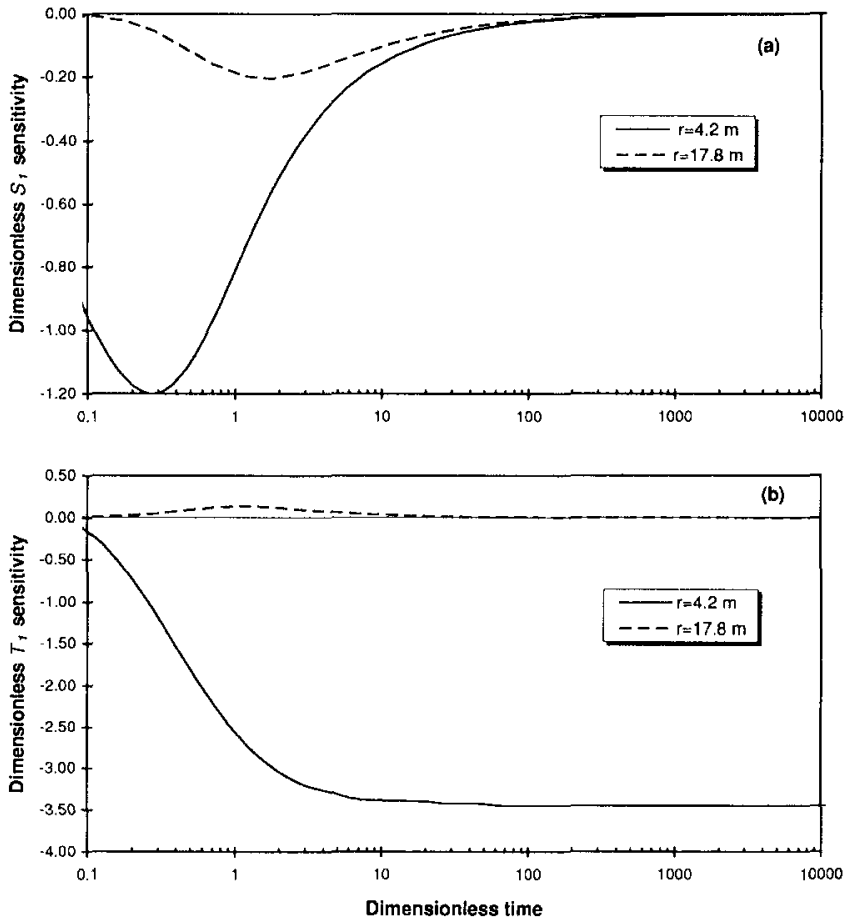

Fig. 4. Change of normalized sensitivities of dimensionless drawdowns $\left[\left(4 \pi T_{2} s\right) / Q\right]$ in inner and outer zones to (a) storativity, and (b) transmissivity of inner zone with dimensionless time $\left(T_{2} t / S_{2} I^{2}\right)$. $\left(T_{1}=600 \mathrm{~m}^{2} / \mathrm{d}, S_{1}=1 \times 10^{-4}, T_{2}=900 \mathrm{~m}^{2} / \mathrm{d}, S_{2}=2 \times 10^{-4}\right)$. 
well can still give some information about the storativity downstream, but it gives little information about transmissivity downstream. Consequently, it is possible to estimate $S_{1}$ using the drawdown in Zone 2, but it is much more difficult to estimate $T_{1}$ using the drawdown in Zone 2.

Note the temporal change in the sensitivity of drawdown in Zone 2 (at $r=17.8 \mathrm{~m}$ ) to $T_{1}$. It increases to a maximum and then gradually decreases with time. Considering Figure $2 b$, this seems typical for the sensitivity of drawdown upstream to the transmissivity downstream.

Figure 5a depicts the sensitivity behavior of dimensionless drawdown $\left[\left(4 \pi \mathrm{T}_{2} \mathrm{~s}\right) / \mathrm{Q}\right]$ to $\mathrm{S}_{2}$ with dimensionless time $\left(\mathrm{T}_{2} \mathrm{t} / \mathrm{S}_{2} \mathrm{l}^{2}\right)$. In both wells the sensitivities increase and then maintain a maximum for the duration of pumpage. At the beginning, the sensitivity in the well at $17.8 \mathrm{~m}$ is slightly greater than that of the well at $4.2 \mathrm{~m}$. In terms of parameter estimation of $S_{2}$, both wells are almost equally good, although at the beginning, the well in Zone 2 may be slightly better.

Figure $5 b$ shows the sensitivity of drawdown to $T_{2}$. In both wells, during most of the pumping time, the sensitivity continues to increase with time. The two observation wells, which are located in different zones and are over $13 \mathrm{~m}$ apart, show almost the same sensitivity. The sensitivity of drawd own in Zone 1 to $T_{2}$ is even slightly greater than that of drawdown in Zone 2 . This is significantly different from the sensitivity of drawdown to $T_{1}$, and also different from the behavior of sensitivity to $S_{2}$. It implies that the drawdown in Zone 1 is theoretically more informative in terms of estimating $\mathrm{T}_{2}$, although the difference is small.

\section{Implications on Parameter Estimation: A Hypothetical Example}

The above discussion shows that transmissivity and storativity have significantly different characteristics, as indicated by different sensitivity features. The influence of these characteristics on parameter estimation in nonuniform aquifers is examined using the aquifer configuration and parameters shown in Figure 3. The drawdowns are calculated and then used as "observed" data to estimate the true parameters by the Gauss-Newton optimization method. Because the data are error-free, the parameters can be estimated accurately even when the sensitivity is very small. It is therefore not possible to discuss the effects of drawdown insensitivity on flow property estimation. Some kind of artificial error must be added before these drawdown data are used. Many researchers use artificially generated errors for hypothetical discussion (e.g., Knopman and Voss, 1987; Yeh and Sun, 1985). Most of them assume that error is normally distributed with an arithmetic mean of zero and a variability which depends on the noise level. The normally distributed error is also used in this discussion. It is assumed that the variability is dependent on the average drawdown with respect to time.

The radial numerical model (Rushton and Chan, 1976) is run with the true parameters (see Figure 3), exact drawdowns are
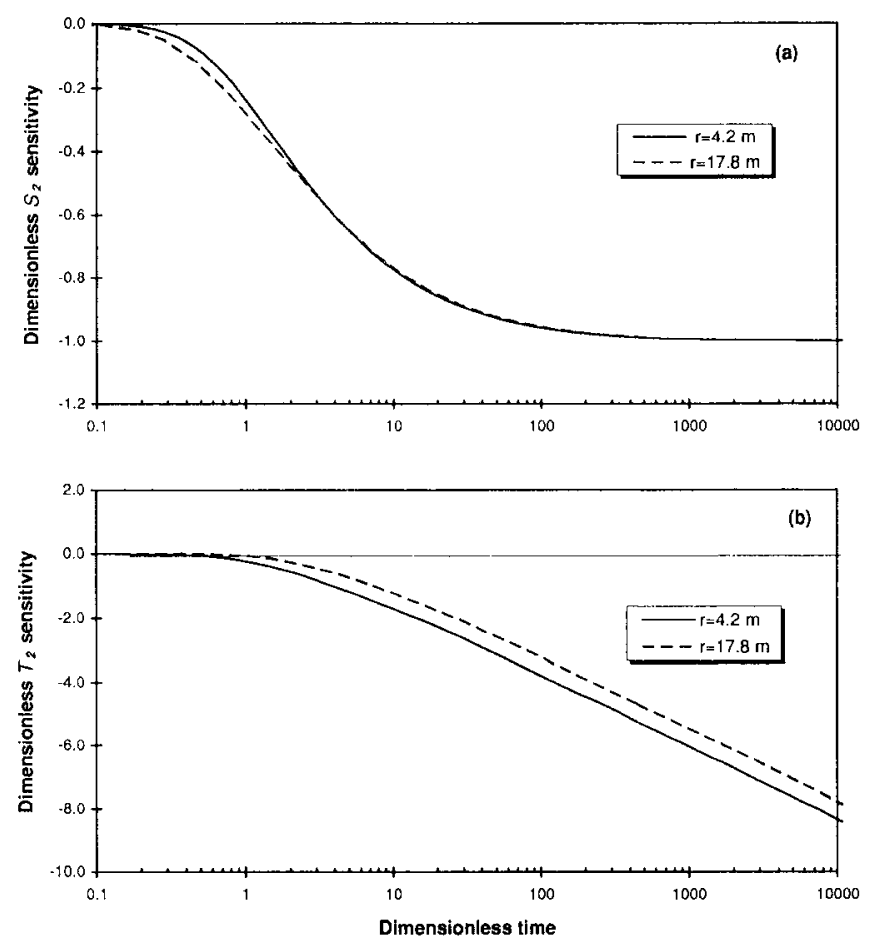

Fig. 5. Change of normalized sensitivities of dimensionless drawdowns $\left[\left(4 \pi T_{2} s\right) / Q\right]$ in inner and outer zones to (a) storativity, and (b) transmissivity of outer zone with dimensionless time $\left(T_{2} t / S_{2} l^{2}\right)$. $\left(T_{1}=600 \mathrm{~m}^{2} / \mathrm{d}, S_{1}=1 \times 10^{-4}, T_{2}=900 \mathrm{~m}^{2} / \mathrm{d}, S_{2}=2 \times 10^{-4}\right)$.

"observed." Then the drawdowns are "noised" by adding normally distributed errors with a mean of zero and a standard deviation equal to $1 \%$ of the average drawdown of a particular observation well. The "observed" drawdowns are then used to estimate parameters by means of the unconstrained GaussNewton method. The true parameters are used as initial "guess."

As shown in Table 1, the drawdowns in O1 (the observation well in Zone 1) can lead to reasonably good estimation of parameters in both zones. The error in $T_{2}$ is smaller than that of $T_{1}$ but the error in $S_{2}$ is larger than that of $S_{1}$. This is because the sensitivity of drawdown in $\mathrm{O} 1$ to $T_{2}$ is larger than that to $T_{1}$ (see continuous lines in Figures $4 b$ and $5 b$ ), but the opposite is true for the sensitivity to $S_{1}$ and $S_{2}$ (see continuous lines in Figures $4 a$ and 5a). The error in estimated storativity of a particular zone seems smaller when the drawdown in that zone is used, because the drawdown is most sensitive to the storativity near the observation well. When $\mathrm{O} 2$ is used, although it can produce good estimation of the parameters of Zone 2, the estimated parameters in Zone 1, especially $T_{1}$, are highly erroneous; because the sensitivity of drawdown in $\mathrm{O} 2$ to $T_{1}$ is very small, as shown by the broken line in Figure $4 \mathrm{~b}$.

A more general conclusion can be made from this example: an observation well downstream can be used to estimate both transmissivity and storativity downstream as well as upstream, but an upstream observation well may not be used to accurately

Table 1. Estimated Parameter Values with Respect to the Locations of Observation Wells

\begin{tabular}{|c|c|c|c|c|c|c|c|c|}
\hline \multirow{2}{*}{$\begin{array}{l}\text { Well } \\
\text { used }\end{array}$} & \multicolumn{4}{|c|}{ Zone I } & \multicolumn{4}{|c|}{ Zone 2} \\
\hline & $\mathrm{T}_{1}\left(m^{2} / d\right)$ & error $(\%)$ & $10^{4} \mathrm{~S}_{1}$ & error (\%) & $\mathrm{T}_{2}\left(m^{2} / d\right)$ & error (\%) & $10^{4} \mathrm{~S}_{2}$ & error $(\%)$ \\
\hline O1 & 633.6 & +6 & 0.92 & -8 & 901.3 & +0.1 & 1.58 & -21 \\
\hline $\mathrm{O} 2$ & 246.6 & -59 & 0.53 & -47 & 896.4 & -0.4 & 2.02 & +1 \\
\hline
\end{tabular}


estimate downstream transmissivity. Storativity reflects the aquifer's ability to release water; it has the characteristics of two-way coordinates. It depends on both the upstream and downstream portions of the location where it is "sampled" and can be estimated by drawdowns both upstream and downstream. The estimate of $S_{1}$ from the drawdown in Zone 2 is erroneous because, in the radial flow model, the sensitivity of drawdown in Zone 2 to storativity is very small due to the distance from $\mathrm{O} 2$ to Zone 1 . However, the reason for the erroneously estimated $T_{1}$ by drawdown in Zone 2 seems deeply rooted in the characteristics of the parameter. Transmissivity reflects the aquifer's ability to transmit water; it has the property of one-way coordinates. Information on transmissivity can be transferred mainly from upstream to downstream. The information on the transmissivity of the downstream portion of an aquifer cannot be well reflected by the drawdown in the upstream portion aquifer.

This example also shows that parameters estimated from an observation well very near the pumping well can represent the flow properties of both the aquifer portion near the pumping well and the portion in the distance. Parameters estimated from an observation well at distance will, however, represent mainly the flow property of the aquifer between the location of the observation well and the distant portion of the aquifer which is influenced by the pumping. Similar conclusions were also reached by Butler and Liu (1993).

\section{Summary and Discussion}

The different characteristics of transmissivity and storativity under constant-rate pumping conditions have been examined and the influence of these characteristics on parameter estimation investigated using a hypothetical example. The results show that transmissivity has the characteristics of one-way coordinates and storativity has the characteristics of two-way coordinates. Information on transmissivity is transferred mainly from upstream to downstream. More specific conclusions can be presented as: (1) Sensitivity behavior of storativity is significantly influenced by local flow properties, but that of transmissivity is controlled mainly by the general flow properties of the flow field; (2) Drawdown in an observation well is more sensitive to the storativity of a downstream zone than that of an upstream zone, but the difference is not significant; (3) Drawdown in an observation well is more sensitive to the transmissivity of an upstream zone than that of a downstream zone and the difference is very significant. The sensitivity of drawdown to transmissivity of a downstream zone is characterized by a small positive value over a limited time period.

The above conclusions have implications in pumping-test design and parameter estimation in nonuniform aquifers. In order to estimate the parameters of a zone and the background aquifer, an observation well should be located downstream but near to the zone. It should not be placed upstream if the parameters downstream are to be estimated. An upstream well can produce information of storativity of both upstream and downstream, but it cannot produce much information about the transmissivity downstream. Because of the different characteristics between transmissivity and storativity of a nonuniform aquifer, a well may provide adequate information for storativity estimation, but may not provide adequate information for transmissivity estimation. The aquifer area represented by estimated storativity may be different from that represented by estimated transmissivity even when both are estimated from the same data. Estimated storativity may reflect the features of the aquifer downstream more than that of the aquifer upstream, but the estimated transmissivity may represent mainly the features of the aquifer upstream.

In this paper, examples are limited to confined aquifers, but the general conclusions may be true for unconfined aquifers with thickness significantly larger than drawdown. The discussion on the characteristics of aquifer parameters is based on constantrate pumping conditions in one-dimensional flow systems. The characteristics of aquifer parameters under more general conditions, such as regional two-dimensional flow fields, may be different and is a topic for further investigation.

\section{Acknowledgment}

The authors would also like to thank A.L.H. Gameson for his review and constructive criticism of the earlier draft of this paper and the three anonymous reviewers for their many valuable comments. This work is supported in part by a grant from the School of Mines and Energy Department (SOMED) at the University of Alabama.

\section{References}

Beck, J. V. and K. J. Arnold. 1977. Parameter Estimation in Engineering and Science. John Wiley, New York.

Butler, J. J. 1988. Pumping tests in nonuniform aquifers: The radially symmetric case. J. Hydrol. v. 101, no. 1/4, pp. 15-30.

Butler, J. J. and W. Liu. 1993. Pumping tests in nonuniform aquifer: The radially asymmetric case. Water Resour. Res. v. 29 , no. 2 , pp. 259-269.

Butler, J. J. and C. D. McElwee. 1990. Variable-rate pumping tests for radially symmetric nonuniform aquifers. Water Resour. Res. v. 26 , no. 2 , pp. 291-306.

Jiao, J. J. 1993. Sensitivity features of aquifer parameters and their implications on parameter estimation. Ph.D. thesis, School of Civil Engineering, Birmingham Univ., UK.

Jiao, J. J. 1995. Sensitivity analysis of pumping tests in non-uniform aquifers. Hydrological Sciences Journal. v. 40, no. 6 (in press).

Jiao, J. J. and Z. Chen. 1987. An improved characteristic-rectangular finite element method in the solution of two-dimensional waterquality model transport problems. Selected Papers of Hydrogeology and Engineering Geology. no. 6 (in Chinese), pp. 13-24.

Knopman, D. S. and C. I. Voss. 1987. Behavior of sensitivities in the one-dimensional advection-dispersion equation: implications for parameter estimation and sampling design. Water Resour. Res. v. 23, no. 2, pp. 253-272.

McElwee, C. D. 1982. Sensitivity analysis and the ground-water inverse problem. Ground Water. v. 20, no. 6, pp. 723-735.

McElwee, C. D. 1987, Sensitivity analysis of groundwater models. In: Advances in Transport Phenomena in Porous Media, ed. by J. Bear and M. Y. Corapcioglu. NATO Adv. Study Inst. Ser. Ser. E, v. 128, pp. 751-817.

Oliver, D. S. 1993. The influence of nonuniform transmissivity and storativity on drawdown. Water Resour. Res. v. 29, no. 1, pp. 169-178.

Patankar, S. V. 1980. Numerical Heat Transfer and Fluid Flow. McGraw-Hill.

Rushton, K. R. and Y. K. Chan. 1976. A numerical model for pumping test analysis. Proc. Instn. Civ. Engrs. Part 2, v. 61, pp. 281-296.

Sykes, J. F., J. L. Wilson, and R. W. Andrews. 1985. Sensitivity analysis for steady-state groundwater flow using adjoin operators. Water Resour. Res. v. 21, no. 3, pp. 359-371.

Yeh, W.W-G. and N. Z. Sun. 1985. An extended identifiability in aquifer parameter identification and optimal pumping test design. Water Resour. Res. v. 20, no. 12, pp. 1837-1847.

Zheng, C. and G. D. Bennett. 1995. Applied Contaminant Transport Modeling: Theory and Practice. Van Nostrand Reinhold, New York. $440 \mathrm{pp}$. 